\section{The looking time perceptual deprivation effect (PDE): A test of the imitation hypothesis***}

\author{
BRUCE T. LECKART, MARK BUTLER, and R. M. YAREMKO \\ San Diego State College, San Diego, Calif. 92115
}

This experiment tested the hypothesis that the effect of short-term perceptual deprivation on looking time is produced by $S$ 's imitation of the intervals preceding exploration rather than the deprivation encountered during the "depriving" intervals. A 2 by 4 within-Ss design was used in which the duration of the interval preceding free looking trials $(2,15,28$, and $41 \mathrm{sec})$ was orthogonal to the nature of stimulation during these intervals (either darkness in the experimental chamber or the presentation of a colored slide). No evidence in support of the imitation hypothesis was found. The results indicated that when looking was preceded by a colored slide, no systematic relationship was found between looking time and the duration of the interval preceding looking. The results were interpreted in terms of a theory of exploratory behavior based on the concept of an optimal level of arousal.

In the last 20 years, psychologists have increased their investigation of exploratory behavior. Exploratory behavior has become a significant problem for two primary reasons. First, naturalistic observation indicates that much human and animal behavior falls into the category of exploratory behavior. Second, the observations made by researchers in this area are not easily explained within traditional learning-motivation theoretical frameworks (e.g., Hull, 1943).

In the 1950 s most of the research in this area investigated exploratory behavior in animals. However, in the last 10 years, more researchers have studied human exploratory behavior. The paradigms most frequently used by these investigators have involved visual exploration. Accordingly, we find investigations of the determinants of visual selection and/or the duration of attention to or "free" looking time at selected visual stimuli (e.g., Berlyne, 1958; Cantor \& Cantor, 1966; Gaschk, Kintz, \& Thompson, 1968; Faw, Nunnally, \& Ator, 1969; Nunnally, Faw, \& Bashford, 1969; Leckart, Gehres, \& Thornton, 1970; Heinrich, 1970). 1 Generally, this research has been atheoretical, concerning itself primarily with investigations of the parameters of exploratory behavior and relegating the development of a formal theoretical framework to a secondary position. However, one

*The authors wish to thank Mr. James Martin for his assistance in collecting portions of the data and Drs. Philip S. Gallo, John Grossberg, W. A. Hillix, and Mirim Rodin for critically reading a prepublication version of this paper.

**This research was supported by a grant from the $S$ an Diego State College Foundation. general theoretical position taken by a number of researchers is based on the concept of an optimal level of arousal (e.g., Hebb, 1955; Malmo, 1959; Leuba, 1955; Berlyne, 1960; Fiske \& Maddi, 1961). This position stipulates that $S s$ engage in exploratory behaviors because these behaviors are successful either at maintaining an optimal level of arousal or at returning $S$ to the optimal level in the case where S's level of arousal has dropped below the optimal. Typically, they specify that exploratory behaviors provide $\mathbf{S}$ with stimulus change which can increase or maintain S's level of arousal.

One recent finding which promises to have extensive theoretical implications for this position is the discovery of a short-term perceptual deprivation effect (PDE) in human visual exploratory behavior (Leckart, Levine, Goscinski, \& Brayman, 1970). These researchers found that when the opportunity to view visual stimuli was preceded by a brief period of visual deprivation (lights out in the experimental chamber for up to $30 \mathrm{sec}$ ), the time spent looking at or exploring the visual stimulus increased as the duration of deprivation increased. Explanations of that phenomenon in terms of receptor adaptation or avoidance of the dark periods were ruled out, and it was concluded that the PDE was produced by the "depriving" nature of the interval immediately preceding the stimulus. One optimal level of arousal interpretation of this finding specifies that prolonged perceptual deprivation lowers the arousal and that the resulting exploratory behaviors are an attempt to maintain or increase arousal.
Although this interpretation is plausible, other possible explanations of the PDE have not been exhausted. One possibility is that the PDE is not a function of the darkness that precedes the looking stimuli but a function of the length of the interval per se regardless of the stimulation contained in that interval. Support for this hypothesis comes from the finding that presenting stimulation at particular rates prior to exploration influences the duration of the exploratory behavior (Leckart, Keeling, \& Bakan, 1966). In this study, it was found that if, before a period of visual exploration, visual material was presented for viewing for fixed durations that were either longer or shorter than S's operant level looking times, the duration of looking was changed in the direction of the duration for which the material was presented. For example, if S's operant looking time at a set of experimental stimuli is $10 \mathrm{sec} /$ stimulus, presenting him with a series of stimuli that he is allowed to view for only $2 \mathrm{sec} / \mathrm{stimulus}$ results in his looking at the experimental stimuli for somewhat less than his operant rate. Similarly, when $\mathrm{S}$ is forced to look for longer periods than normal, the result is an increase in looking time. The authors hypothesized that the fixed rate of presentation provided a model which $S$ imitated. If the deprivation interval used by Leckart et al (1970) is viewed as a model, an alternative explanation of the PDE is that Ss imitate the deprivation periods.

The present experiment was designed to determine whether the PDE is due to S's imitation of the intervals preceding exploration or the deprivation encountered during the "depriving" intervals. Specifically, the plan was to present two kinds of "deprivation" intervals, one filled with darkness and one filled with stimulation. If the PDE is due to darkness or the absence of stimulation, the PDE should be observable only following darkness and not following identical intervals filled with stimulation. If the PDE is produced by the rate at which the deprivation intervals are presented, then looking time should increase as a function of the interval regardless of whether the interval is filled.

\section{SUBJECTS}

The Ss were $30 \mathrm{male}$ and female college students from the introductory psychology course at San Diego State College. All Ss volunteered to satisfy a class requirement.

\section{APPARATUS}

The Ss were tested in a $1.8 \times 1.8 \mathrm{~m}$ lightproof, sound-attenuated chamber They sat at a table facing a $30 \times 30 \mathrm{~cm}$ rear-projection screen inserted in one 
of the walls. The screen was at eye level and about $75 \mathrm{~cm}$ from S's face. The $20 \times 30 \mathrm{~cm}$ stimuli were projected by a Kodak Carousel 800 projector. Wratten neutral density filters attached to the projector's lens reduced the intensity of the projections by $90 \%$.

The stimuli consisted of 37 different color slides of objects, arrays of objects, and landscapes. They were selected from a group of 129 slides that had been previously rated by 149 Ss on a 7-point scale of complexity (Leckart, 1966). The stimuli were selected from the center of the complexity dimension. The mean complexity rating of the slides was 4.12. Twenty-five stimuli were randomly selected from the group of 37 and used for the free looking trials. A different stimulus was used for each of the 24 trials. The 25 th stimulus was used to start the sequence of trials, but, since it was not preceded by one of the experimental conditions, no looking times were collected for this stimulus. The remaining 12 stimuli were used for filling the intervals between free looking trials with stimulation when called for by the experimental design.

\section{PROCEDURE}

A 2 by 4 within-Ss design was used in which the duration of the interval preceding the free looking trials $(2,15$, 28 , and $41 \mathrm{sec}$ ) was orthogonal to the nature of stimulation during these intervals (either darkness in the experimental chamber or the presentation of a colored slide for viewing). Perceptual deprivation was defined as darkness in the experimental chamber.

A total of 24 free looking trials was administered. A free looking trial consisted of presenting a stimulus which $\mathbf{S}$ was instructed to view until he "finished looking at it." Each free looking trial was preceded by an interval of $2,15,28$, or 41 sec. During the 24 trials, each of the four different intervals was used six times. During half of each set of six intervals, darkness was the prevailing condition in the experimental chamber. For the remaining three intervals, Ss viewed a color slide.

The 24 trials were grouped into three blocks of eight trials each. Within each block, one of each of the eight possible conditions was presented. For each $\mathrm{S}$ for each block, the order of presentations of the eight conditions was completely randomized. In addition, the order in which the 24 free looking stimuli were presented was randomly determined for each S. Similarly, the order in which the 12 stimuli used for filling the intervals between free looking trials were presented was completely randomized for each $\mathbf{S}$.
The Ss were told that the experiment was to investigate changes in the galvanic skin response as a function of external stimulation. Sham finger electrodes were attached to S's left hand, and Ss were told that the leads were attached to a polygraph in the adjacent room. They were told that the effects of three conditions were being investigated and that throughout the experiment they were to attend to the screen in front of them. They were told that sometimes the screen would be dark and that when this was the case they were nevertheless to attend to the screen. They were also informed that at other times stimuli would be automatically presented on the screen and that sometimes they were to terminate these stimuli and that at other times the stimuli would go off the screen automatically. A small low-intensity red light came on with and went off with the stimuli that Ss were asked to terminate. The red light was placed approximately $10 \mathrm{~cm}$ below the right-hand side of the screen. In all cases, the stimuli were projected automatically. The free looking stimuli were terminated by S's pressing a button held in his right hand. The stimuli used to fill the intervals preceding the free looking stimuli were a utomatically terminated. Looking times were automatically recorded to the nearest $0.1 \mathrm{sec}$.

\section{RESULTS}

Eight scores were obtained for each $S$ : the mean looking times for stimuli preceded by darkness or stimulation for intervals of $2,15,28$, and 41 sec. The means of these scores are presented in Fig. 1. Inspection of the figure indicates that for the darkness condition the looking times increased as the duration of the interval was increased from 2 to $41 \mathrm{sec}$. Figure 1 also indicates that for the stimulation condition, the relationship between the duration of the interval and looking time is both smaller and nonmonotonic.

An analysis of variance indicated significant differences in looking times as a function of the nature of stimulation during the intervals preceding the free looking trials $(F=5.48, \mathrm{df}=1 / 29, \mathrm{p}<.01)$ and the duration of the interval $(F=7.78$, $\mathrm{df}=3 / 87, \mathrm{p}<.01)$. The interaction between the nature of stimulation during the interval and the duration of the interval was also significant $(\mathrm{F}=30.42, \mathrm{df}=3 / 87, \mathrm{p}<.01)$.

In order to determine the locus of the differences between means for the various intervals employed, Duncan's new multiple range test was separately applied to the four means in both the deprivation and the slide condition. The results of the range test for the intervals preceded by deprivation revealed significant differences between 2 and $15 \sec (p<.01), 2$ and 28 sec $(p<.01), 2$ and 41 sec $(\mathrm{p}<.001)$, and 15 and 41 sec $(\mathrm{p}<.01)$. The difference between 15 and $28 \mathrm{sec}$ was not significant. The difference between 28 and $41 \mathrm{sec}$ narrowly failed to reach a significant level, with the difference between looking times in these conditions being $1.7 \mathrm{sec}(\mathrm{df}=87)$, with a 1.73 needed for significance at the .05 level with $\mathrm{df}=60$ and 1.71 needed for significance with $\mathrm{df}=120$.

The results of the range test for the interval preceded by stimulation revealed that the only significant difference between means was between intervals of 2 and $28 \mathrm{sec}$ $(\mathrm{p}<.05)$.

The results of the present experiment replicate the perceptual deprivation effect (PDE) discovered by Leckart et al (1970) in that preceding a free looking test stimulus with periods of perceptual deprivation resulted in increased free looking times. It was also found that the relationship between the duration of perceptual deprivation and the duration of looking was direct throughout the range of intervals investigated.

The most important finding of the present experiment was the demonstration that the PDE is not an artifact produced by Ss' imitation of the interval preceding the free looking stimulus. When darkness prevailed in the interval preceding the free looking stimuli, looking time was directly related to the duration of the darkness. However, when a colored slide was presented in the interval preceding the free looking stimulus, no such systematic relationship was observed.2 Thus, the present experiment very strongly suggests that the PDE is produced by the reduction of stimulation in the period immediately preceding exploration. This finding is consistent with earlier observations that indicate that there is an increase in S's search for and exploration of stimuli as a function of perceptual deprivation (Jones, 1966; Schultz, 1965). However, the primary difference between the present and earlier experiments is the duration of deprivation employed. The present experiment used deprivations on the order of seconds, whereas the earlier research used deprivation on the order of hours.

The present experiment may have important implications for both a general theory of motivation and a specific theory of exploratory behavior. The theoretical position favored by the authors is similar to Hebb's (1955) unitary drive concept. This position postulates that organisms 


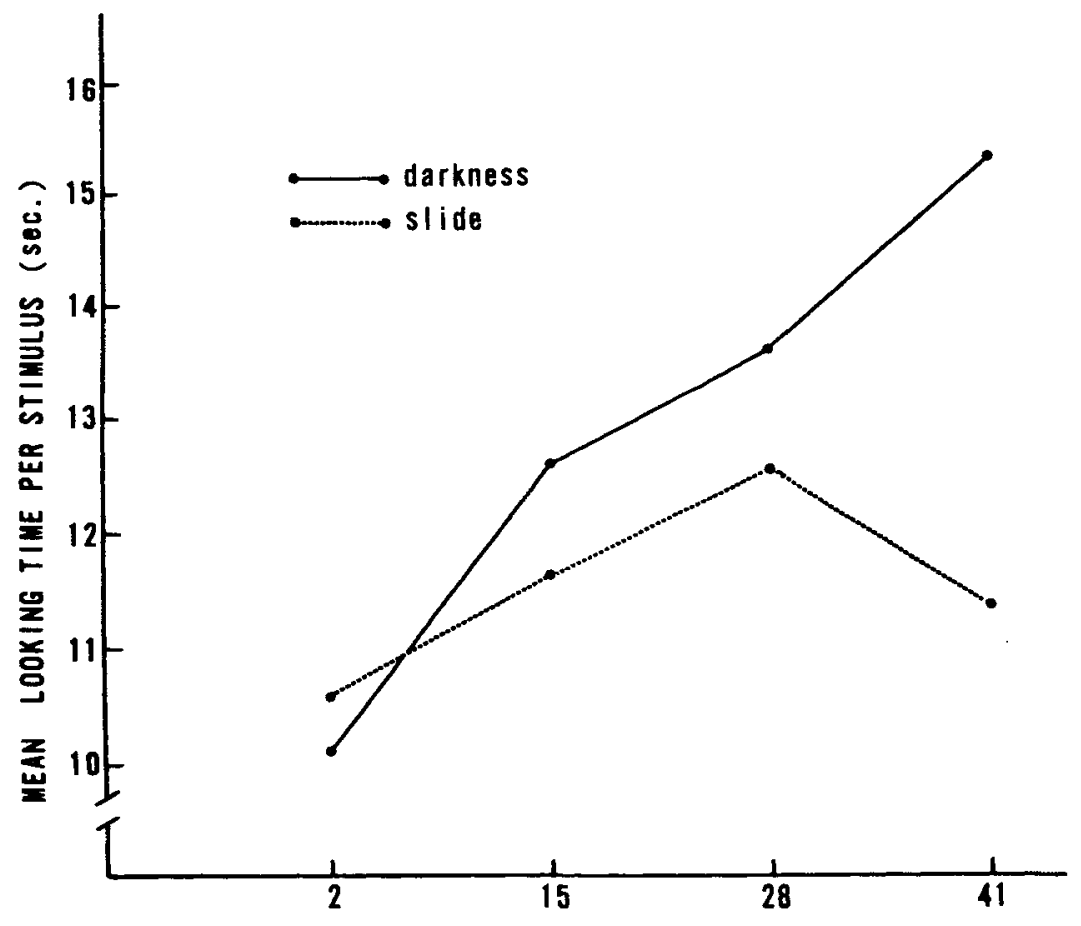

DURATION OF THE INTERYAL PAECEDING FREE LOOKIng(sec.)

Fig. 1. Mean looking time as a function of the duration of deprivation and the nature of stimulation during the interval preceding the free looking stimuli.

behave in ways that maintain some moderate or optimal level of arousal in a postulated neural center. Accordingly, if environmental conditions cause S's arousal level to depart from the optimum in either direction, $S$ will behave in ways which tend to direct arousal toward the optimal level. Similarly, when environmental conditions permit, Ss will behave in ways which prevent the level of arousal from departing from the optimum. In the case where arousal is either below the optimum or in danger of being reduced below the optimum, $\mathbf{S}$ will engage in behaviors that have been collectively labeled by psychologists as exploratory behaviors. These behaviors serve to raise the level of arousal when it is reduced below the optimum and to maintain an optimal level of arousal when the arousal level is in danger of being reduced below the optimum. The specific manner in which exploratory behaviors have their effect is through exposing the organism to stimulus change. It is supposed that stimulus change affects the organism by raising the level of arousal. It is also supposed that previously investigated stimulus variables such as "novelty," "complexity," "incongruity," etc., affect behavior by providing stimulus change. Thus, Ss continue to explore, or keep themselves exposed to, a stimulus as long as that stimulus provides sufficient opportunity for stimulus change, either to maintain the optimal level of arousal or to move $S$ in the direction of the optimum. However, as the stimulus becomes exhausted as a result of continued exposure (i.e., habituation), it fails to provide $\mathbf{S}$ with sufficient change and arousal. At this point, the organism behaves in a manner which exposes it to a situation which provides sufficient stimulus change and arousal.

The current position is very explicit about the determinants of the duration and selection of exploratory behaviors: whether $S$ continues exposing himself to a current stimulus configuration or selects new stimuli to attend to or explore is determined by S's position on the arousal scale with respect to the optimum and the direction and rate of movement with respect to the optimum.

This position can easily be applied to the present experiment. It is supposed that $S$ obtains stimulus change as he scans the stimulus and that this stimulus change produces arousal. When the opportunity to obtain stimulus change is denied by the enforced period of perceptual deprivation, the level of arousal decreases continuously from the optimum. Thus, as the length of the deprivation is increased, the distance $S$ is from the optimum at the termination of deprivation is also increased. If one assumes that the farther $S$ is from the optimum, the less stimulus change is needed to produce an increase in the level of arousal, the explanation of the perceptual deprivation effect is clear. The long looking times that occur following long periods of deprivation stem from the ability of the stimulus to provide prolonged increases in the level of arousal because of S's distant position from the optimum. That is, when $S$ is far from the optimum, little stimulus change is needed to produce a given increase in arousal. Consequently, the arousal-producing potential of the stimulus is exhausted slowly. Similarly, the short looking times that occur following brief periods of deprivation stem from the inability of the stimulus to provide prolonged arousal because of S's close proximity to the optimum. That is, when $S$ is close to the optimum, a large amount of stimulus change is needed to produced a given increase in arousal. Consequently, the arousal-producing potential of the stimulus is rapidly exhausted. Preceding the looking-time stimulus with a slide results in a smaller reduction in the level of arousal because stimulus change obtained during that exposure helps to maintain a more nearly optimal level of arousal. Consequently, Ss look for briefer durations when the interval preceding the looking-time stimulus provides greater opportunities for stimulus change.

\section{REFERENCES}

BERLYNE, D. $E$. The influence of complexity and novelty in visual figures on orienting responses. Journal of Experimental Psychology, 1958, 55, 289-296.

BERLYNE, D. E. Conflict, arousal, and curiosity. New York: McGraw-Hill, 1960.

CANTOR, J. H., \& CANTOR, G. N. Functions relating children's observing behavior to amount and recency of stimulus familiarization. Journal of Experimental Psychology, 1966, 72, 859-863.

FAW, T, T, NUNNALLY, J, C, \& ATOR, N. A. The influence of stimulus uncertainty and experimental instructions on visual selection. Perception \& Psychophysics, 1969, 5, 137-140.

FISKE, D. W. \& MADDI, S. R. Functions of varied experience. Homewood, II: Dorsey Press, 1961.

G A SCHK, A., KINTZ, B. L., \& THOMPSON, R. W. Stimulus complexity free looking time, and inspective exploration. Perception \& Psychophysics, $1968,4,319-320$.

HEBB, D. O. Drives and the C.N.S. (conceptual nervous system). Psychological Review, 1955, 62, 243-254. HEINRICH, P. "Free looking time": Eine Methode zur Praferenzbestimmung. Psychologie und Praxis, 1970, 14, 79-93.

HULL, C. L. Principles of behavior. New Yodk: Appleton-Century-Crofts, 1943.

JONES, A. Information deprivation in humans. In B. A. Maher (Ed.), Progress in experimental personality research. Vol. 4 New Y ork: Academic Press. 1966.

LECKART, B. T. Looking time: The effects 
of stimulus complexity and familiarity. Perception \& Psychophysies, 1966, 1, 142-144.

LECKART, B. T. GEHRES, L.. \& THORNTON, G. Looking time: Experimenter and instruction effects. Perception \& Psychophysies, 1970, 8. 54-56.

LECKART, B. T., KEELING, K. R., \& BAKAN, P. The effect of rate of presentation on tree looking time. Pexception \& Psychophysics, 1966, 1, 107-109.

LEC KART, B. T., LEVINE, J. R., GOSCINSKI, C., \& BRAYMAN, W. Duration of attention: The perceptual deprivation effect. Perception \& Psychophysics, 1970, 7, 163-164.

LEUBA, C. Toward some integration of learning theories: The concept of optimal stimulation. Psychological Reports, 1955 , 1, 27-33.
MALMO, R. B. Activation: A neuropsychological dimension. Psy chological Review, 1959, 66, 367-386. NUNNALLY, J. C., FAW, T. T., \& BASHFORD, M. B. The effect of degrees of incongruity on visual fixations in children and adults. Journal of Experimental Psychology, 1969, 81, $360-364$.

SCHULTZ, D. P. Sensory restriction effects on behavior. New York: Academic Press, 1965.

\section{NOTES}

1. In the human exploratory behavior literature, the terms "looking time"" "free looking time," and "duration of attention" are synonomous and refer to the time $S$ spends viewing a stimulus under instructions to "look for as long as you wish" or "look until you are finished viewing." The present paper used the term "looking time" exclusively.

2. In fact, the only difference between intervals in the slide condition was an increase in looking time between 2 and 28 sec. One possible interpretation of this unexpected difference suggests that viewing a slide for $28 \mathrm{sec}$ (which is about double the slide's operant looking time) may have been depriving, in that little stimulus change was available to $S$. However, suggesting that prolonged looking at a complex visual stimulus may be depriving would lead one to expect an increase in looking time between 28 and $41 \mathrm{sec}$. But, there was actually a small, although not significant. decrease in looking time between 28 and 41 sec. Thus, no simple interpretation of the difference between 2 and $28 \mathrm{sec}$ can be made without additional research. 